\title{
A Study on the Motivations and Attitudes of Chinese Students Towards Learning Two Foreign Languages in Junior Middle School
}

\author{
Xinyu Liu ${ }^{1, *}$ \\ ${ }^{1}$ College of Foreign Languages, Nankai University, Tianjin, 300071, China \\ *Corresponding author. Email:liuxinyu1108@ sina.cn
}

\begin{abstract}
A few junior middle schools in China have encouraged students to learn another foreign language besides English and set specialized classes for this group of people. Some students choose to join this kind of class at the cost of gaining much burden as they have one more compulsory course than others. Drawing on qualitative research, the researcher used both questionnaires and interviews as methods to determine their motivations. Furthermore, this study aimed to investigate their attitudes towards this multi-lingual education based on their personal experience. Data were collected from undergraduates and postgraduates who have learnt two foreign languages in their junior middle schools. Results indicate that a wide range of people decided to do so since mastering a foreign language is an additional skill that can increase their chance of accepting better higher education. Most participants considered they benefited from multilingual teaching in junior middle school, believing that it will draw more and more attention and thus further develop. However, there are also some participants who held a negative attitude, so this study also gives some advice towards its future.
\end{abstract}

Keywords: Second Language Acquisition (SLA), Third Language Acquisition (TLA), Junior Middle School, Multi-lingual Education, Chinese Students

\section{INTRODUCTION}

In the face of the continuous development of economic globalization and cross-cultural communication, especially the Belt and Road Initiative, mastering two foreign languages has gradually become a necessity for future inter-disciplinary talents.

The Ministry of Education of the Republic of China (MOE) attaches great importance to the reform of multilingual education in junior middle schools by making a series of guiding recommendations for the introduction of minority language courses [1]. Furthermore, since 2013, the foreign language subject in college entrance examinations is no longer limited to English. Five minority languages, namely Japanese, Russian, German, French and Spanish, are also good choices with lower difficulties.

Given that junior middle school students have less academic pressure. A few schools in China, especially foreign language schools, set specialized classes in response to the policy of MOE. Students who accept this multi-lingual education will learn a minority language as one more compulsory course besides English. This research will focus on the motivations of students who have accepted this kind of education in their junior middle schools and also their attitudes after graduation based on personal experience towards this.

Thus, these findings contribute to adopting patterns of teaching two foreign languages in junior middle schools on a large scale and better integrating them into the future Chinese education system.

\section{RESEARCH METHODOLOGY}

\subsection{Theoretical Basis}

This research aims to identify people's motivations and attitudes. As a qualitative study, it should produce a narrative, descriptive account of a setting or practice [2], thus whose paradigm is interpretivism instead of positivism. Based on interpretivism, a theory emerges from specific conditions, and it is 'grounded' in the facts collected by the study [3]. In other words, the theory 
should come after research, not before it. To build it, the researcher in this study engages directly with experience and understanding [4].

\subsection{Research Object}

Since junior middle school students can be easily influenced by their parents or others, the subjects in this research were 57 graduates and postgraduates ( 25 and 32 respectively) who have learnt two foreign languages in their junior middle schools.

The number of subjects in the face-to-face interviews was ten, and that in the online interviews was 15 . The number of subjects in the online questionnaire was 32, of which 30 were valid.

\subsection{Research Methods}

This research adopts mainly face-to-face and online interviews, as well as online questionnaires to express and verify the research questions, both of which compensate for each other's limitations.

The interview method is flexible and has a high degree of authenticity and validity but lacks anonymity, and the participants are easily influenced by the interviewer. By contrast, the questionnaire method allows for more efficient data collection, also considering participants' anonymity. In this circumstance, Participants are less likely to be distracted by others and are more likely to express their actual views.

Therefore, this mixed-method is the most appropriate way to get data.

For subjects who attended interviews, necessary instructions had been given. All the participants provided verbal informed consent. For data collection purposes, audio recordings of interviews were used to investigate further. They were all saved in a password-protected laptop for the sake of data security.

Some questions related to the gist of interviews are modified to constitute the questionnaire. Subjects who filled out the questionnaire were given the appropriate information on its purpose and so forth to ensure that all of the subjects could complete the questions honestly and accurately. The questionnaire is anonymous, and all their information would be kept secret. After the data were collected, they were carefully examined to guarantee that all of them are valid for study.

\section{RESULTS AND FINDINGS}

\subsection{Motivation}

\subsubsection{Intrinsic Motivations}

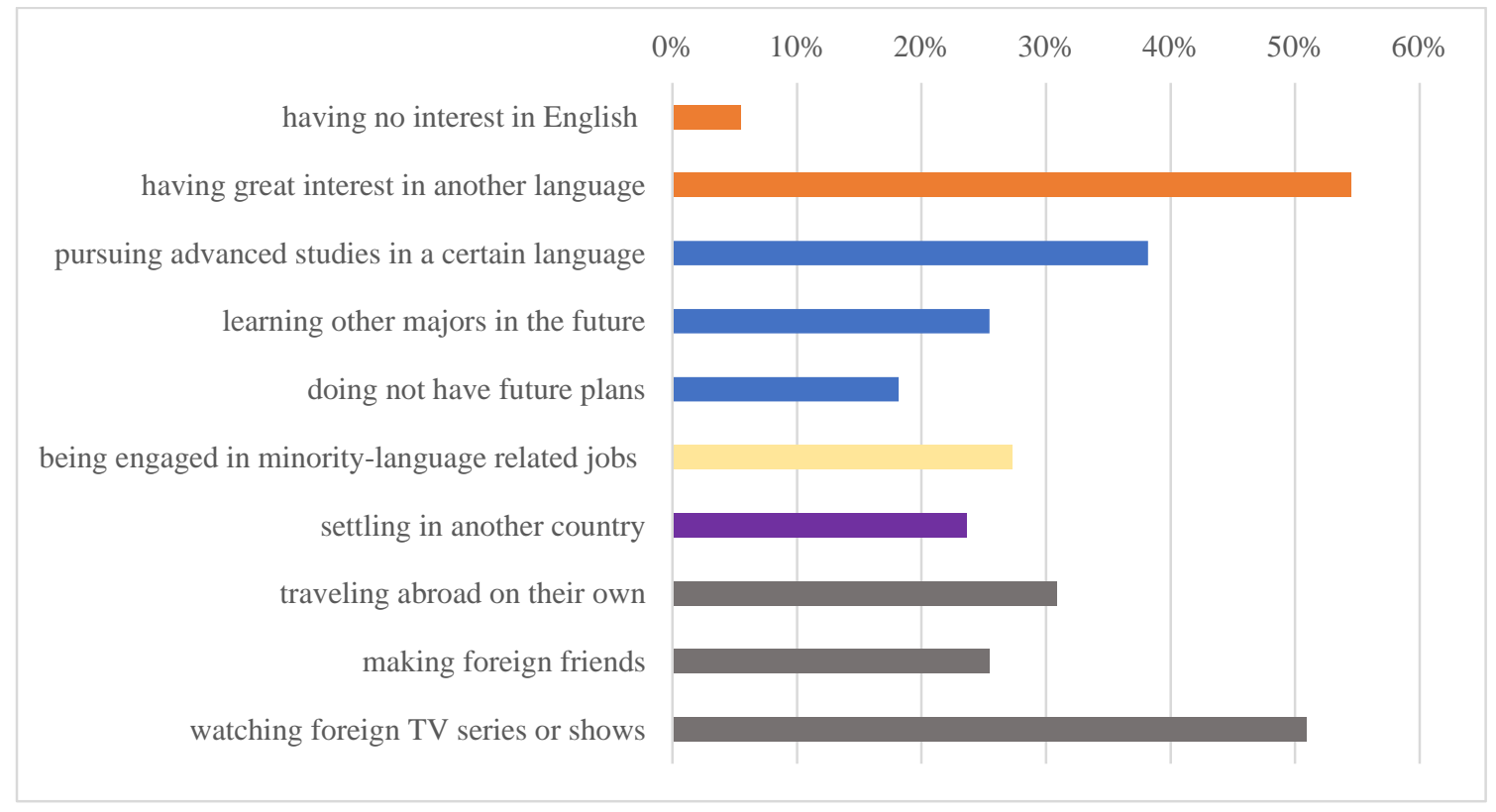

Figure 1. Intrinsic Motivations towards Learning Two Foreign Languages in Junior Middle School

\subsubsection{Interest}

$5 \%$ of students learn a minority language by reason that they are not interested in English. By choosing to study another language, they can have fewer English classes in a week. Oppositely, 55\% students have great interest in one minority language when they are junior middle students. For example, Japanese anime precedes and excels among the whole world, which definitely attracts many teenagers in China. Students who are fond of watching anime tend to choose Japanese. First, they expect to watch the anime without subtitles, understand 
the lines and even imitate those characters. Second, they desire to learn more about Japan, including its history and culture. There are also students who are interested in the language itself like some think French is romantic. Overall, many students chose to learn their second foreign language due to their interests.

\subsubsection{Future Major}

Students who have clear future goals in junior middle schools choose their second foreign language on purpose. $38 \%$ want to pursue advanced studies in a certain language in higher education, so they learn it in advance to lay a solid foundation for future learning. Suppose they stand out and rank high in the test, in that case, they can get the chance as a recommended candidate enrolled by ideal universities without requiring entrance examinations, which is a particular policy in the enrolment system of higher learning institutions and other key universities of China.

While some students hope they can learn other majors in the future, they tend to choose a minority language based on their specific needs. According to the data from the questionnaire, if students set a goal of learning engineering technology, they probably will learn German since whose industry is in the dominant and leading position around the world. Communication without barriers is beneficial to their future education abroad.

Students who do not have future plans accept this multi-lingual education for broadening choices of future majors, as well as considering they will have one more option of foreign language subject in the college entrance examination.

\subsubsection{Future Profession}

As junior middle school students start exploring their identity, they may dream about what kind of person they will become and what kind of career path they will be engaged in. This group of people, who give priority to the professions instead of majors, accounts for about $29 \%$. Unfortunately, there are extremely few students who want to be engaged in language teaching or education in the future as their life-long career.

\subsubsection{Migration}

$24 \%$ students have longer-term plans. They study a minority language because they want to go abroad for jobs or even settle in that country as an expatriate. A participant in our interview attended a prestigious firstclass university in Japan, then worked there engaging in the financial circles and lived in Japan for years, and all struggled alone. Unlikely, some of the students have relatives who already lived in another country. Finding that they all achieved in some areas, students also want to find a job there. More students want to go abroad owing to this as they think they will have someone to rely on in foreign lands and places.

\subsubsection{Social Life}

A majority of students learn a second foreign language for enriching their social lives. They want to travel abroad on their own, communicate with foreigners, even making friends with them. Some girls learn Korean because they like binge-watching Korean TV series and talent shows.

\subsubsection{Extrinsic Motivations}

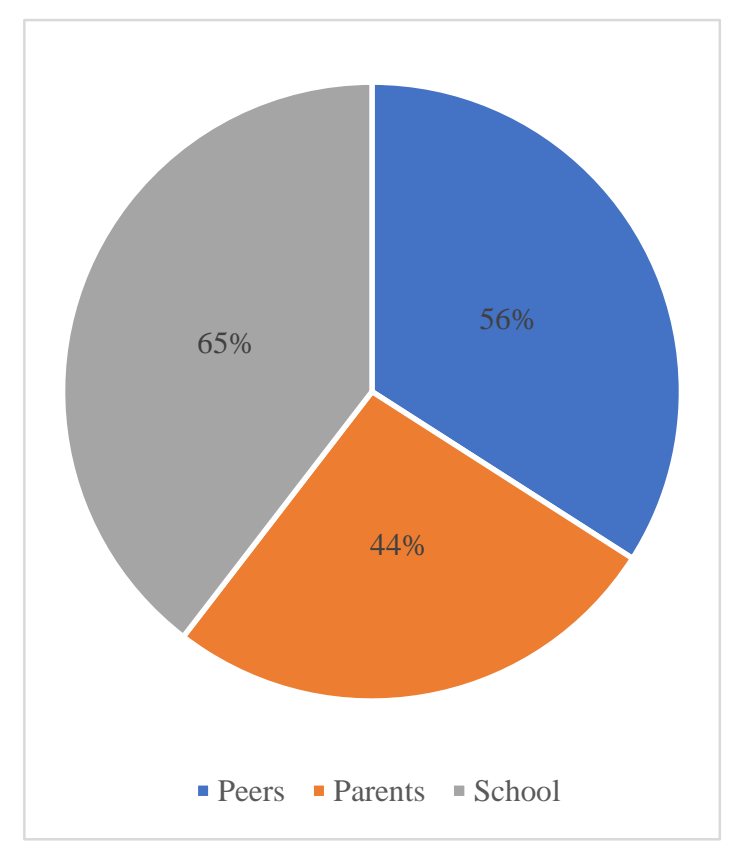

Figure 2 Extrinsic Motivations towards Learning Two Foreign Languages in Junior Middle School

\subsubsection{From Peers}

Junior middle school students are, to some extent, sensitive because of adolescence. As a result, they may be desperate for peer recognition and admiration. Some participants admitted that they got a sense of superiority when they decided to get involved in two foreign language learning. They feel they are quite different from others as they have the chance to get into such a special type of class and learn one more language than others.

\subsubsection{From Parents}

Junior middle school students lack exposure to society and life experience, and parents usually have some control over their decisions. This leads to that some parents think about if this multi-lingual education fits their child based on their insights into the academic choices, employment pressures and social development. 
It cannot be avoidable that maybe children's intrinsic motivations are also impacted by their parents.

\subsubsection{From School}

The school that established a minority foreign language curriculum has a separate entrance examination and admissions process, and all primary school graduates are encouraged to participate in this scheme. Students will not refuse this great opportunity as they will have one more chance to be admitted by a top-ranked middle school.

The schools follow the national curriculum standards and plan to strengthen the foreign language curriculum. They offer many foreign languages, usually including English, Japanese, German, French and Spanish. Taking one school as an example, it implements the multilingual training model of "one major and one minor", i.e. each student majors in the first foreign language and minors in the second.

In this school, English is reinforced for students whose first language is minor, and the "dual foreign language" teaching system is implemented. For students whose first foreign language is English, the second foreign language can be chosen independently and is taught in a class selection and mobile learning system [5].

All the language teaching are taught in small classes and a conversational style. In virtue of less academic pressure in junior middle school, this unique teaching program attracts many students, or to say their parents. But this also leads to that some students choose a minority language that is easier to learn rather than which they like. Some even are not interested in language learning at all but are forced to complete the credits.

\subsection{Attitudes}

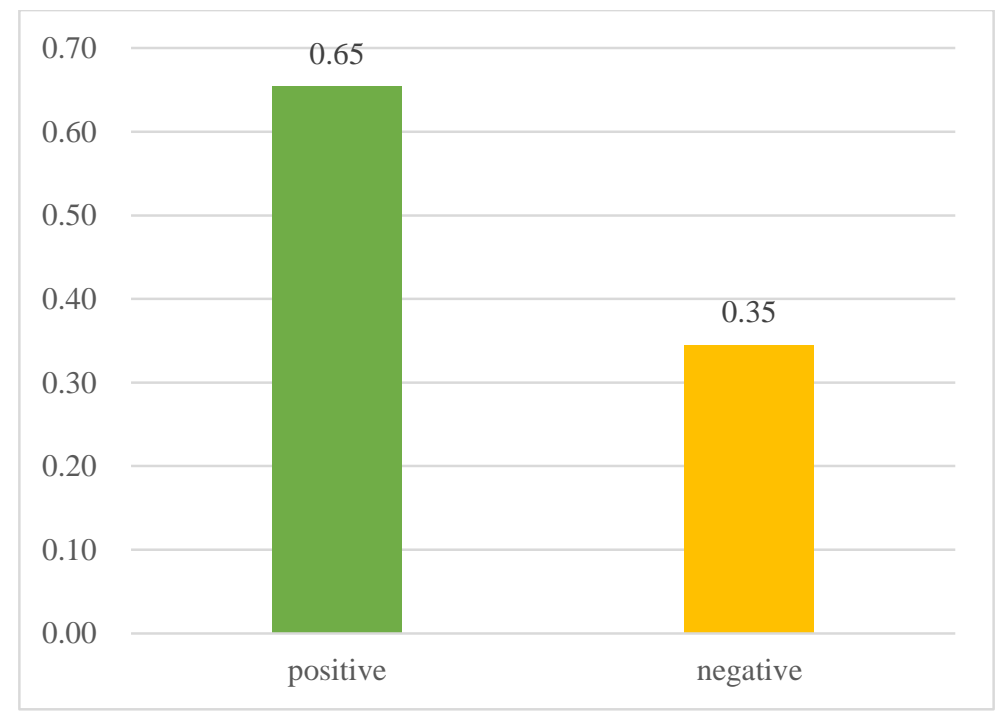

Figure 3. Attitudes towards Learning Two Foreign Languages in Junior Middle School

\subsubsection{Positive}

Most of the students feel that learning two foreign languages in junior middle school have benefited them in some aspects of their lives and believe that mass teaching of two foreign languages would also be a trend. Firstly, the two foreign languages have a mutually reinforcing effect and further expand their minds. Secondly, mastering two languages will also make them more competitive on campus and in the future workplace. Some students also suggest that when choosing a second language, it may be more beneficial to choose a language from the same language family as the first one, which may make learning less difficult.

\subsubsection{Negative}

Students with negative views see learning a second language as merely a compulsory part of their junior middle education and do not make a significant difference to their future professional direction and life.

Some students even gave up halfway through their studies because they felt overwhelmed. A few students do not regret learning two foreign languages but regret their choice of learning a minority language instead of another one. They believe that the teaching of a second foreign language in junior high school is not complete.

What is more, many of them think that languages are just tools. Translation software is evolving at a rapid pace so that there is little demand for language talents. They 
see no sign and no reason for MOE to launch the teaching of two foreign languages on a large scale in the future.

\section{ANALYSIS AND DISCUSSION}

Since the junior middle students are not mentally perfect and their thoughts are not mature, their learning motivations are affected by extrinsic motivation mainly [6]. Thus, knowing students' motivations of learning two foreign languages is significant. For students themselves, their learning attitude, interest and attention in class to master knowledge are all depend on their motivations [7]. For teachers and other educators, they can develop a better teaching way or issue relevant policies according to students' motivations and attitudes.

According to the theory of cognitive development stages [8], children between 12 and 15 are in the Formal Operational Stage. Children are used to forming and revising their own ideas, and this is where parent and school guidance is essential. For parents, may think teenagers are not mature and thus give excessive intervention on school and language choice. However, students need to have a say in their own life decisions that parents can give some advice or help organize their ideas.

Schools should also respect and leave room for students' decisions by offering them the opportunity to change their choice. Firstly, the school can conduct and give minority language briefing sessions to make sure that students and their parents have a better understanding of each language without personal bias. Secondly, in some junior middle schools, students make their language choices in order according to their grade ranking, which makes some students cannot fulfill their expectations. Schools can change strategies to take students' wants into account and try to balance them with students' rank. For example, students with good grades can be allowed to change their major after one semester or one year of enrolment.

Many surveys on the Critical Period Hypothesis [9] in SLA have shown that the language learning potential declines rapidly in late adolescence [10]. Thus, middle school is a vital point of time for language learning.

In terms of students' occupation, career development theory [11] defined a sequence of life stages, including the growth stage (approximately from ages 4 to 13), the exploration stage (approximately from ages 14 to 24). Chinese teenagers experience this transition in middle school.

Nevertheless, when they are in junior middle schools, they are in the golden age of language acquisition but while also in a vague, idealistic state of thinking about career exploration [12]. At that time, they may want to work in a minority language or two foreign languages related jobs in the future but ultimately find no ideal ones. As can be seen from the negative attitudes collected in this research, many students do not actually make use of it. They may need some instructions as they chose a different education system from most other students, which could lead to a different path.

For future development, junior middle schools that organize the teaching of several foreign languages can, under the leadership of national policy, launch joint training programs with several universities, companies and even state agencies in order to guarantee the employment of multi-language students and retain elite minority language talent. A green channel can be provided for them.

\section{CONCLUSION}

Towards learning two foreign languages in junior middle school, students have a variety of intrinsic motivations, but they may be mainly affected by extrinsic motivations.

As for the attitudes reported by this research, most of them hold a positive attitude but there are many obstacles to be solved of multi-lingual education before it is going to be on a massive scale and in other academic periods.

Adolescence is crucial for language learning, which needs more researchers to delve deeper into it associated with TLA. Indeed, the present paper has many shortcomings and insufficiency. A significant limitation is the amount and range of data collection needed for the analyses. Some other research methods can be used in future research, like a more detailed case study focusing on merely one middle school. In terms of motivations and attitudes of students, different generations and regions might also affect micro-level dynamics. Therefore, the results of the study highlight the need for future research to use a larger or more representative sample.

This topic can also be further investigated from a different perspective, such as the parents or the government. These are all promising areas of research to which this study might be extended.

\section{ACKNOWLEDGMENTS}

I am indebted to Associate Prof. Liam Gearon and Dr. Chenkai Chi for inspiring lectures and comments, and to Ms. Yufan Huang for generous help during this whole research journey.

This research would not have been possible without the support of my parents, friends and so many participants who volunteered to take questionnaires or interviews for this study. I own great thanks to them.

My gratitude also goes to my school-College of Foreign Languages, Nankai University. 


\section{REFERENCES}

[1]Ministry of Education of the Republic of China. (2018). Letter of Response to Proposal No. 0013 (Education No. 006) of the First Session of the 13th National Committee of the Chinese People's Political Consultative Conference

[2]Drislane, R., \& Parkinson, G. (2011). Qualitative research. Online dictionary of the social sciences.

[3]Glaser, B. G., \& Strauss, A. L. (2017). Discovery of grounded theory: Strategies for qualitative research. Routledge.

[4]Cohen, L., Manion, L., \& Morrison, K. (2018). Research methods in education (eight edition). Abingdon, Oxon.

[5]Tianjin Foreign Languages School. (2021). Admission brochure for junior middle school students of Tianjin Foreign Languages School. https://mp.weixin.qq.com/s?search_click_id=1023 1091354666425178-1632366994519-

$648216 \&$ subscene $=19 \& \_$_biz $=$MzA4Mzk4MzkzM $\mathrm{g}==\& \mathrm{mid}=2651462769 \& \mathrm{id} \mathrm{x}=1 \& \mathrm{sn}=$ fcbcc $904 \mathrm{e} 58 \mathrm{a}$ bc814c13932a4320b207\&chksm $=84109722$ b3671 e34cdec6ca67c88a0bb25495375a0a03c022a6268e e2d8c95452937fcfa

[6]Min, A. (2010). On Training and Stimulate Students Learning Motivation, Modern reading. The ninth Perid.

[7]Long, C., Ming, Z., \& Chen, L. (2013). The Study of Student Motivation on English Learning in Junior Middle School--A Case Study of No. 5 Middle School in Gejiu. English Language Teaching, 6(9), 136-145.

[8]Piaget, J. (1951). The child's conception of the world (No. 213). Lanham, MD: Roman \& Littlefield.

[9]Penfield, W., \& Roberts, L. (2014). Speech and brain mechanisms. Princeton University Press.

[10]Hartshorne, J. K., Tenenbaum, J. B., \& Pinker, S. (2018). A critical period for second language acquisition: Evidence from 2/3 million English speakers. Cognition, 177, 263-277.

[11]Super, D. E. (1980). A life-span, life-space approach to career development. Journal of vocational behavior, 16(3), 282-298.

[12]Shuhua Zhang, \& Lulu Ye. (2010). A study on the developmental characteristics of adolescents' career exploration. Journal of Shenyang Normal University: Social Science Edition (5), 83-86. 